\title{
Nitrogen and yield potential of irrigated rice
}

\author{
M. J. KROPFF' ${ }^{\prime}$ K. G. CASSMAN ${ }^{1}$, H. H. VAN LAAR ${ }^{2}$, and S. PENG ${ }^{1}$ \\ I International Rice Research Institute, P.O. Bo. 933,1099 Manila. Philippines. 2 Department of \\ Theoretical Production Ecology, Wageningen Agricultural University, P.O. Box 430, 6700 AK \\ Wageningen, The Netherlands
}

Key words: Nitrogen, rice, simulation, model

\begin{abstract}
Yield potential of modern rice varieties and implications for $\mathrm{N}$ management were evaluated in a series of field studies that provided data for validation of an eco-physiological simulation model for rice. We tested the hypothesis that $\mathrm{N}$ was the major factor limiting yield potential of irrigated rice. The simulation model ORYZA1 was used to evaluate the observed yield differences between varieties grown with different $\mathrm{N}$ management and in different environments. The model explained differences in yield of the treatments resonably well on the basis of differences in radiation, temperature, leaf $\mathrm{N}$ content and variety coefficients for phenological development. It was demonstrated by the model and experimental data that yield levels of $6 \mathrm{tha}^{-1}$ in the wet season and $10 \mathrm{t} \mathrm{ha}^{-1}$ in the dry season can be obtained in the tropics with the current short duration varieties only when the $\mathrm{N}$ supply from soil and fertilizer is adequately maintained at key growth stages. Yield probabilities for rice crops were simulated for different environments using long term weather data at two Philippine sites.
\end{abstract}

\section{Introduction}

Projections based on population growth rates in countries where rice is the main food crop, indicate that rice production must increase $65 \%$ by 2020 (IRRI, 1989). This increase must come from increased production per unit area (IRRI, 1989). However, a decline in rice productivity has been observed in high-yielding, intensive, rice-cropping systems (Flinn et al., 1982). On IRRI's experimental farm, rice yielded $10 \mathrm{t} \mathrm{ha}^{-1}$ in the late sixties with the first semi-dwarf variety IR 8 , but recent dry season yields generally did not exceed 6-7 $\mathrm{t} \mathrm{ha}^{-1}$ at recommended fertilizer rates. It was not known if this was related to the genetic yield potential of recent varieties. It was hypothesized that the current low yields at IRRI's farm were partly related to a change in the $\mathrm{N}$ supply environment causing low $\mathrm{N}$ concentrations in leaf tissue, especially during the grain filling period, resulting in early senescence of leaves and low rates of photosynthesis (Kropff et al., 1993a, b; Cassman et al., 1993a, b).

In this paper, we evaluate rice yield potential in relation to plant $\mathrm{N}$ status, and identify the most sensitive parameters for explaining yield differences due to variety, season, and $\mathrm{N}$ supply with an eco-physiological simulation model.

\section{Materials and methods}

\section{Experimental}

In the 1991 wet season (WS) and the 1992 dry season (DS) two improved semi-dwarf indica rice varieties (IR72 and IR58109-113-3-3-2) were grown at three $\mathrm{N}$ levels at the IRRI Research Farm in Los Baños, Philippines. Three twelve-days-old seedlings were transplanted at $20 \times 20 \mathrm{~cm}$ spacing. Treatments were as follows: in the WS, 0,80 , and $110 \mathrm{~kg} \mathrm{~N} \mathrm{ha}^{-1}$; in the DS, 0,180 , and $225 \mathrm{~kg} \mathrm{~N} \mathrm{ha}^{-1}$. The rates in 
the highest $\mathrm{N}$ treatments included a late application at flowering to maintain leaf $\mathrm{N}$ status during grain filling ( $30 \mathrm{~kg} \mathrm{~N} \mathrm{ha}^{-1}$ in the WS and $45 \mathrm{~kg} \mathrm{~N} \mathrm{ha}^{-1}$ in the DS). Transplanting occurred on July 13 (WS) and January 16 (DS). Treatments were arranged in a split plot design with $\mathrm{N}$ rates as the main plots and varieties as subplots, with four replicates. At the major phenological stages and in between, 12 hill samples were taken from each plot to monitor Leaf Area Index (LAI), dry matter, and $\mathrm{N}$ accumulation in stems, leaf blades, and panicles. At maturity a $5 \mathrm{~m}^{2}$ sample was taken as well to determine total dry weight and grain yields.

The model ORYZAI

The eco-physiological rice crop model ORYZA1 used here has been described by Kropff et al. $(1993 \mathrm{c})$. The model simulates phenological development, dry matter production of the plant organs, and leaf area development. The model calculates daily canopy $\mathrm{CO}_{2}$ assimilation by integrating instantaneous rates of leaf $\mathrm{CO}_{2}$ assimilation. The photosynthesis characteristics of single leaves depend upon the specific leaf nitrogen content ( $\mathrm{g} \mathrm{N} \mathrm{m^{-2 }}$ leaf). Input requirements of the model are: geographical latitude, daily weather data (radiation, minimum

\section{Grain yield (kg/ha)}

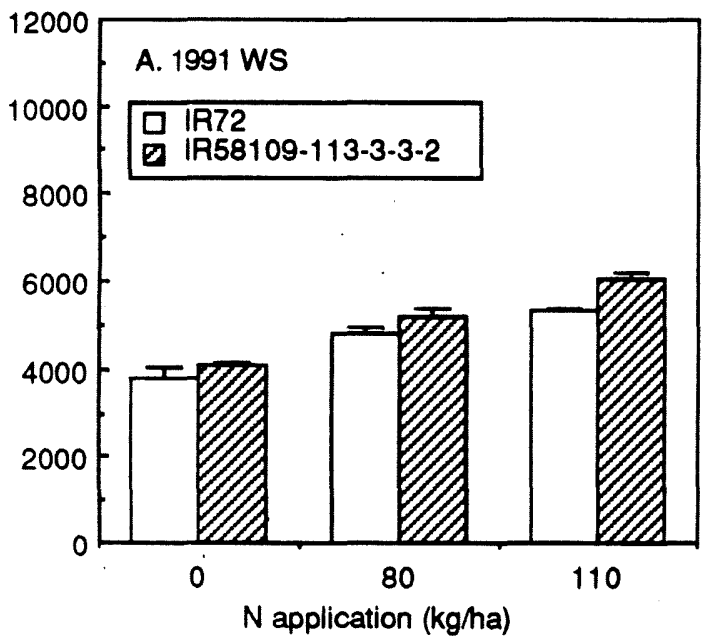

and maximum temperature), plant density, date of seedling emergence and transplanting and parameter values that describe the morphophysiological characteristics of the plant species. Time step of integration is one day.

\section{Results and discussion}

Grain yields with highest $\mathrm{N}$ inputs were comparable to yields reported in the late $1960 \mathrm{~s}$ for IR8 (Yoshida, 1981): about $6 \mathrm{t} \mathrm{ha}^{-1}$ in the WS and $9-10 \mathrm{t} \mathrm{ha}^{-1}$ in the DS (Fig. 1). These yield levels indicate that genetic yield potential has not changed, despite the decreased growth duration (IR72 has a growth duration of about 115 days versus 125 days for IR 8). However, nitrogen input requirements to obtain these yields at the IRRI farm have increased.

The model was used to assess the relative contributions of environmental variables, varietal characteristics and the $\mathrm{N}$ status of the crop to the observed differences in yield. For that purpose, the model was run with different sets of inputs and simulated yields were compared to observed yields for all $\mathrm{N}$ treatment $\times$ variety $\times$ year means. In the first step, the model was run with averaged values of input variables and model coefficients but with actual data for solar

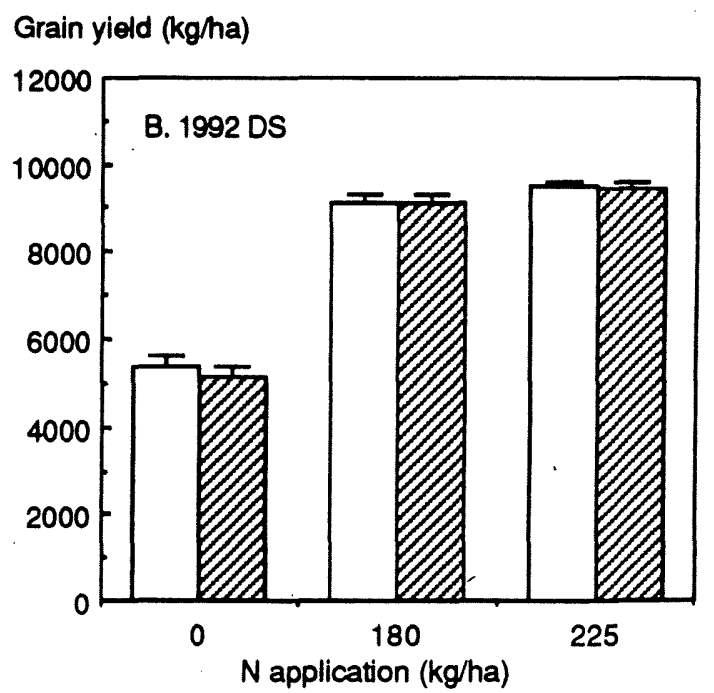

Fig. 1. Grain yield (14\% moisture) of IR72 and IR58109-113-3-3-2 at different rates of N application in the 1991 Wet Season (A) and the 1992 Dry Season (B). 
radiation (SR) and temperature $(T)$ for the two planting dates (Fig. 2A). The regression analysis shows that only $56 \%$ of the variation was explained and the relationship between observed and simulated yields strongly deviated from the $1: 1$ relationship. If in addition to $S R$ and $T$ the variety-specific coefficients for development rates in the vegetative phase (DVRV) and the grainfilling phase (DVRR) were used, the regression line came closer to $1: 1$, but no additional variation was explained (Fig. 2B). Adding the effect of $\mathrm{N}$ status on the relative growth rate of the leaf area (RGRL, in the $-\mathrm{N}$ treatments this value was lower) increased the $r^{2}$ ( $86 \%$ of total variation), although the deviation from the $1: 1$ relationship remained similar (Fig. 2C). Good simulations were obtained by adding the actual measured specific leaf $\mathrm{N}\left(\mathrm{g} \mathrm{m}^{-}\right)$of each of the 12 treatments. This gave a relation close to the $1: 1$ line and $r^{2}=0.95$ (Fig. 2D).
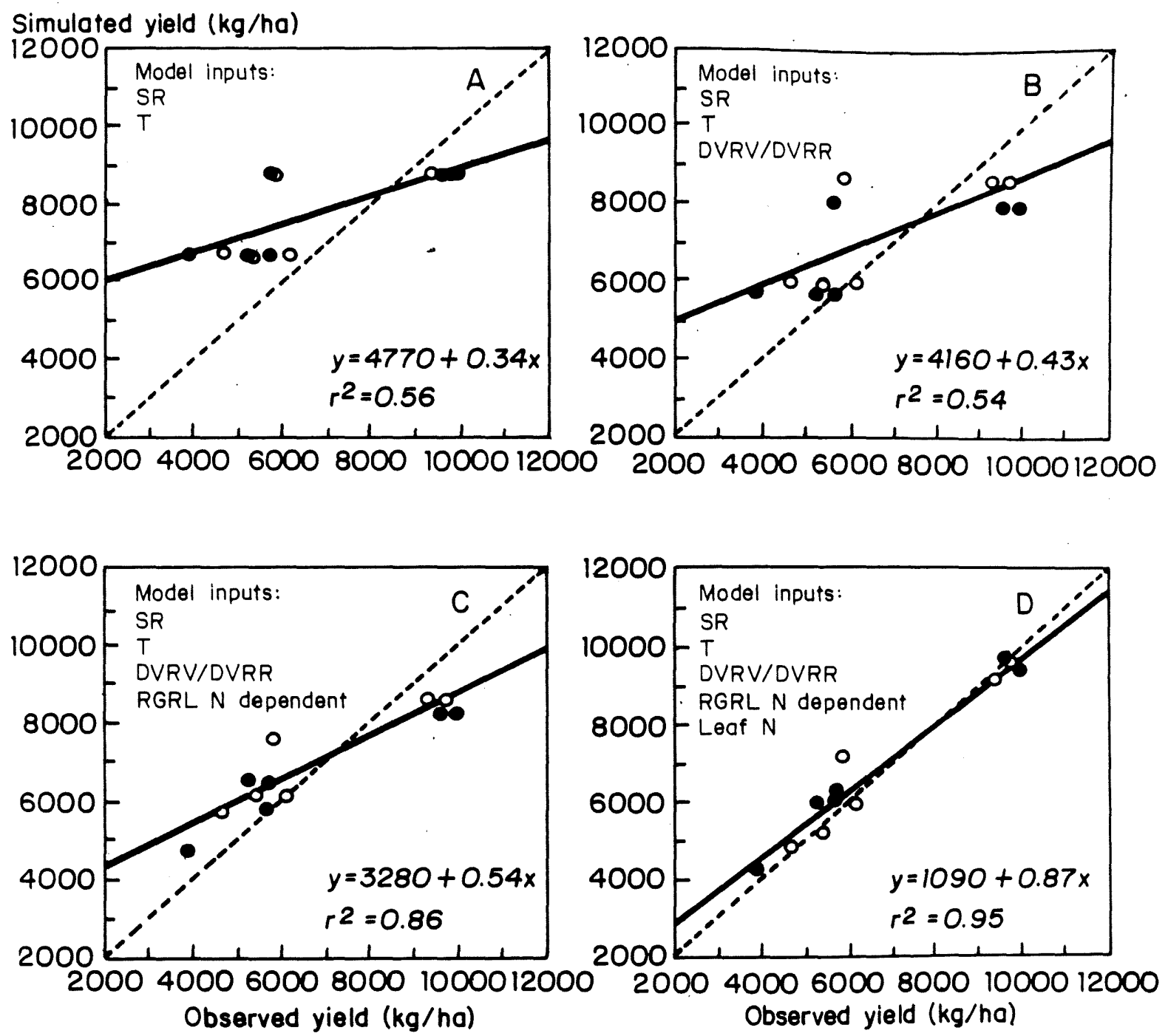

Fig. 2. Simulated rice yields in relationship to observed yields in 12 treatments (two varieties IR72 (open symbols) and IR58 109113-3-3-2 (closed symbols); two seasons 1991 WS and 1992 DS; and three N levels in each season) with different model inputs (see text). 
This analysis shows that the large differences in yield between the 12 treatments can be explained by the eco-physiological model using a small number of variables, of which the specific leaf $\mathrm{N}$ is a key component.

The model was subsequently used to determine the potential yield probabilities using long term weather records from two sites, based on parameterization for IR72 using 1992 DS
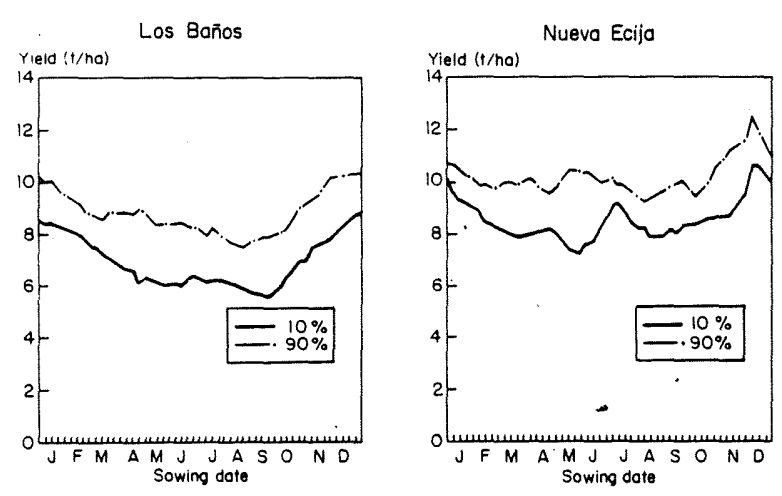

Fig. 3. Yield probabilities of IR72 as a function of date of transplanting as simulated by the model ORYZA1 for Los Baños and Nueva Ecija (Philippines) using long-term weather data and using the leaf $N$ contents measured in the 1992 DS high $\mathrm{N}$ treatment as model input. The lines indicate the yields that are exceeded on more than $90 \%$ or $10 \%$ of the years.

data. This analysis demonstrates the large within-year and year-to-year variation in yield potential that results from differences in weather conditions at IRRI (International Rice Research Institute, Los Baños, Fig. 3A) and for a research station $300 \mathrm{~km}$ north of Los Baños (Nueva Ecija, Fig. 3B), where differences in dry and wet season are not as distinct, and where yield potential is higher than at IRRI. The importance of leaf $\mathrm{N}$ was analysed by comparing simulated yields using leaf $\mathrm{N}$ as measured in the high $\mathrm{N}$ treatments of the WS (relatively low) and DS (relatively high) experiment. It was found that a high leaf $\mathrm{N}$ status has much more impact in the DS than in the WS at both sites. For example, higher leaf $\mathrm{N}$ increased the $75 \%$ probability yield from 6.0 to $7.6 \mathrm{t} \mathrm{ha}^{-1}$ in the wet season and from 7.1 to $9.7 \mathrm{t} \mathrm{ha}^{-1}$ in the dry season. We conclude that it is essential to match $\mathrm{N}$ supply to the requirements of the crop to achieve full yield potential in intensive irrigated rice systems. Because the effective soil- $N$ supply remains relatively constant at $60-80 \mathrm{~kg} \mathrm{~N} \mathrm{ha}^{-1}$ in continuously irrigated rice system (Cassman et al., 1993b), the $\mathrm{N}$ uptake requirements have to be met by fertilizer application at the key growth stages. Simulation approaches can be used to quantify the $\mathrm{N}$ uptake requirements at these growth stages for specific target yield levels, which will help to maximize $\mathrm{N}$ use efficiency.

\section{References}

Cassman, K.G., Kropff, M.J. and Zhende Yan, 1993a. In: Proceedings of the 1992 International Rice Research Conference, IRRI (in press).

Cassman, K.G., Kropff, M.J., Gaunt, J. and Peng S., 1993b. In: Proceedings of the XII International Plant Nutrition Colloquium Perth, Western Autralia.

Flinn, J.C., De Datta, S.K. and Labadan, E., 1982. Field Crops Research 5, 201-216.

IRRI, 1989. International Rice Research Institute, P.O. Box 933, 1099 Manila, Philippines, 66 p.

Kropff, M.J., Cassman, K.G. and van Laar, H.H., 1993a. In: Proceedings of the 1992 International Rice Research Conference, IRRI (in press).

Kropff, M.J., Cassman, K.G., Penning de Vries, F.W.T. and van Laar, H.H., 1993b. Journal of Agricultural Meteorology 48, $795-798$.

Kropff, M.J., van Laar, H.H. and ten Berge, H.F.M., 1993c. International Rice Research Institute, P.O. Box 933, 1099 Manila, Philippines, 89 pp.

Yoshida, S., 1981. International Rice Research Institute, P.O. Box 933, 1099 Manila, Philippines, 269 p. 